\title{
UMA ESTÉTICA DEMOCRÁTICA EM JOSÉ SARAMAGO
}

\section{DEMOCRATIC AESTHETICS IN JOSÉ SARAMAGO}

Deivis Jhones Garlet* Rosani Ketzer
RESUMO: Os estudos acerca da obra de José Saramago caracterizam-se pela predominância de temas ligados ao humanismo, à democracia à solidariedade, à exploração socioeconômica, entre outros. Igualmente, posição do autor enquanto cidadão, que reiteradamente critica a imposiça de interesses mercantis sobre a politica, deturpando a democracia vigente na maior parte dos países da aluallidade, tambem figura em diversas análses. Tomando tais caracteristicas como base, pontuamos a necessidade de se reconhecer a democracia em José Saramago em um nivel formal, mais precisamente na estrutura romanesca (aqui delimitada ao plano das açós). Argumentaremos que a estrutura do romance saramaguiano é dialetica, viabilizando a realizaçao plena do conteúdo democrático sem recair no ufanismo absoluto. Com uma análise de Ensaio sobre a lucidez, pretendemos objetivar a abstrata estrutura dialética para, então, sugerir uma qualificação para a estetica sarama-

PALAVRAS-CHAVE: Romance; José Saramago; democracia; dialética; estética.
* deivisjh@hotmail.com

Doutor em Letras, Estudos Literários; Mestre em Letras, Estudos Literários; Especialista em Pensamento Político Brasileiro e graduado em Historia, todos pela Universidade Federal de Santa Maria.

rosaniumbach@mail.com

Doutora em Neuere Deutsche Literatur, pela Freie Universität Berlin Mestre em Letras e graduada em Letras e Comunicação Social, pela Universidade Federal de Santa Maria. Pesquisadora 1D do CNPq e
professora titular da UFSM.

ABSTRACT: The studies about José Saramago's oeuvre are characterized by the predominance of themes related to humanism, democracy, solidarity, economic exploitation, among others. Equally, the position of the author as a citizen, which presents reiterated criticism of the imposition of mercantile interests over politics, harming current democracy in the majority of the countries, also appears in several analyses. Having such characteristics as a basis, we point out the need for recognizing democracy in Jose Saramago in a formal level, more preisely in the romanesque structure (here delimited to the actions plan). We argue that the novel structure of Saramago is dialectical, enabling the complete realization of the democratic content without reflecting in absolute boastfulness. By means of an analysis of Seeing, we intend to objectify the abstract dialectical structure in order to, then, suggest aesthetics.

KEYWORDS: Novel; José Saramago; democracy; dialectic; aesthetics. 
1. SARAMAGO. Democracia e universidade.

2. SARAMAGO. As palavras de Saramago, p. 388.
Um dos escritores contemporâneos que mais se destacou no ativismo em prol da democracia foi, seguramente, o português José Saramago. Possuidor de uma percepção aguda da realidade dos tempos hodiernos, manifestou-se intensamente por meio de entrevistas, conferências, reportagens, blogs e eventos diversos, com uma crítica contundente às imposições do mercado na esfera política (e na subjetividade dos indivíduos), especialmente pelo fato de que os centros de poder econômico mundiais não são democráticos, pois não apresentam espaços de participação popular, tampouco visam ao bem comum. ${ }^{1}$ Segundo o autor português, a democracia vigente na maior parte dos países ocidentais é insuficiente, uma vez que "A democracia não pode se limitar à simples substituição de um governo por outro. Temos uma democracia formal, mas precisamos de uma democracia substancial". É nesse sentido que, pedagogicamente, exorta os ouvintes por ocasião de uma conferência realizada em Santiago, no Chile, em 2003:

Que fazer, então? Deixar de considerar a democracia como um dado adquirido, definido de uma vez e para sempre intocável. Num mundo que se habituou a discutir tudo, uma só coisa não se discute, precisamente a democracia [...]. Pois eu digo: discutamo-la, meus senhores, discutamo-la a todas as horas, discutamo-la em todos os foros, porque, se não o fizermos a tempo, se não descobrirmos a maneira de a reinventar, sim, de a re-inventar, não será só a democracia que se perderá, também se perderá a esperança de ver um dia respeitados neste infeliz planeta os direitos humanos. E esse seria o grande fracasso da nossa época, o sinal de traição que marcaria para todo o sempre o rosto da humanidade que agora somos. ${ }^{3}$

A forte posição de José Saramago enquanto cidadão é harmônica com a de intelectuais críticos ao regime democrático vigente, tido como insuficiente e manipulado por instâncias autoritárias. Segundo a filósofa Marilena Chaui,

a democracia, modelada sobre o mercado e sobre a desigualdade socioeconômica, é uma farsa bem-sucedida, visto que os mecanismos por ela acionados destinam-se apenas a conservar a impossibilidade efetiva de democracia. Se, na tradição do pensamento democrático, democracia significa: a) igualdade, b) soberania popular, c) preenchimento das exigências constitucionais, d) reconhecimento da maioria e dos direitos da minoria, e) liberdade, torna-se óbvia a fragilidade democrática no capitalismo. ${ }^{4}$

Ao lado das suas manifestações extraliterárias, o autor trabalhou na construção de uma obra ficcional que, em consonância com o pensamento do Círculo de Bakhtin, ${ }^{5}$ reflete e refrata o sentimento de insatisfação perante a questão democrática: o extraestético é estetizado. A crítica literária, ${ }^{6}$ por
3. SARAMAGO Democracia universidade, p. 72-73.
4. CHAUI. Cultura e democracia: o discurso competente e outras falas, p. 148.

5. MEDVIÉDEV. O método forma nos estudos literários: introduçáo crítica a uma poética sociológica. critica a uma poética sociologica.

6. Sobre a recepção crítica da obra saramaguiana no Brasil, ver OZELAME. O duplo, a lucidez e a morte: olhares críticos. 
7. No atual estágio da pesquisa que desenvolvemos, percebeu-se uma estrutura dialética (tomando-se por referência o plano das ações nos romances: Levantado do

chão, A caverna, Ensaio sobre a cegueira, Ensaio sobre a lucidez As intermitências da morte. Também se verifica uma estrutura dialética nos romances cujo teor se caracteriza nos parâmetros da metafiç̧âo historiográfica, como História do cerco de Lisboa e $\mathrm{O}$ ano da morte de Ricardo Reis. seu turno, tem enfatizado os elementos do conteúdo político e ideológico contidos nas narrativas do escritor, concedendo ênfase a aspectos como o humanismo, a democracia e a solidariedade. Todavia, uma significativa parcela dos estudos acaba por se limitar a um sociologismo, no qual o texto literário é tido como documento que comprova uma afirmação extraliterária do escritor, ou mesmo como uma confirmação dos problemas da democracia atual, em uma perigosa relação direta de causa e efeito. Devemos salientar, no entanto, a pertinência de diversos outros estudos, os quais refletem acerca de elementos formais que viabilizam o conteúdo político-ideológico contido na obra saramaguiana. Argumentaremos, tomando a crítica precedente como ponto de partida, que o conteúdo axiológico de teor democrático se realiza por meio de uma estrutura (aqui delimitada ao plano das ações) indelevelmente dialética, impedindo a redução do ficcional ao panfletário. Sendo tal argumento apropriado, pode-se pensar a estética de José Saramago como democrática, quer na forma quer no conteúdo. Procederemos, inicialmente, a uma breve definição de democracia para, em seguida, abordarmos a especificidade do literário. A dialética, aqui esboçada segundo os paradigmas de Marx, Lefebvre e Kosik, por sua vez, será apresentada junto à análise literária. Diante das limitações de um artigo, agiremos de maneira ad hoc, enfocando o romance Ensaio sobre a lucidez, considerado como representativo de uma estrutura presente também nas demais obras do autor.
A democracia, para estabelecermos um protocolo conceitual, possui como princípios basilares a liberdade e a igualdade. Nesse sentido, pode-se proclamar a liberdade e a igualdade dos cidadãos quanto ao direito ao sufrágio, dos partidos em livre concorrência e, logo, teremos uma democracia formal. ${ }^{8}$ Por outro lado, pode-se questionar se a liberdade e a igualdade se estendem ao nível econômico e social, e então pensarmos em uma democracia substancial. ${ }^{9}$ Não obstante as demais problemáticas da democracia, direta ou indireta, representativa ou participativa, interessa-nos salientar que, no mundo atual, é de difícil sua presença efetiva, uma vez que os espaços de participação democrática são escassos e controlados por elites comprometidas com o capital, e a substância praticamente inexiste, restando algumas regras procedimentais. Além disso, o cientista político italiano concede uma importância capital ao dissenso, como característica necessária para um regime democrático:

Quero dizer que, num regime que se apoia no consenso não imposto a partir do alto, alguma forma de dissenso é inevitável e que apenas onde o dissenso é livre para se manifestar o consenso é real, e que apenas onde o consenso é real o sistema pode proclamar-se com justeza democrático. Por isto afirmo existir uma relação necessária entre democracia e dissenso, pois, repito, uma vez admitido que democracia significa consenso real e não fictício, a única possibilidade que temos de verificar se o consenso é real é verificando o seu contrário. ${ }^{10}$
8. BOBBIO. O futuro da democracia.

9. BOBBIO. Estado, governo, sociedade: para uma teoria geral da política.
10. BOBBIO. O futuro da democracia, p. 75 
11. SARAMAGO. Levantado do chão, p. $178-195$.

12. SARAMAGO. Memorial do convento, p. 50-59.
Pode-se perceber, portanto, que o dissenso é fundamental para a consecução de um consenso, sob o signo da liberdade e da igualdade. Consenso que poderá (e deverá) ser transformado continuamente. A dialética, então, pode ser compreendida como consoante à democracia, uma vez que é pela tensão de contradições que promove uma síntese, igualmente em devir.

Na obra romanesca de José Saramago, a repressão ao dissenso por parte dos setores detentores do poder é uma tônica, bastando aqui lembrarmos a atitude autoritária do governantes em Ensaio sobre a cegueira, os quais confinam os cegos em um manicômio desativado, submetendo-os a toda sorte de horrores, sem a menor abertura para o diálogo a exemplo da comunicação estabelecida por meio de uma gravação de voz, ou pela truculência dos soldados diante do pedidos de remédios e de comida por parte dos cegos (sem mencionar a violência entre os próprios cegos); também avessa à democracia é a posição da tríade Latifúndio-EstadoIgreja em Levantado do chão, como sucede na cena em que os soldados da guarda torturam campesinos; ${ }^{11}$ igualmente exemplar da ação antidemocrática é a violência da atuação da inquisição em Memorial do convento, como acontece na cena do auto de fé; ${ }^{12}$ ou a imposição predatória dos interesses do Centro em A caverna, fazendo implodir o pequeno artesanato; e, ainda, o autoritarismo levado ao paroxismo em Ensaio sobre a lucidez, com o governo assassinando as personagens que simbolizam o dissenso. A imposição arbitrária dos interesses dos setores ligados ao poder (político, econômico, religioso) é frequente na ficção saramaguiana, ressaltando-se a também constante antítese ao autoritarismo. Porém, essa constatação é de superfície, uma vez que manifesta ostensivamente nos aspectos temáticos do texto literário. Há que se perceber uma proposição democrática mais entranhada, $e$ que se manifesta na interrelação entre a forma e o conteúdo, aquela realizando este.

Entre os elementos formais já levantados pela crítica literária, e que são indicativos de uma estética democrática em José Saramago, podemos citar: a multiplicidade de vozes relativamente autônomas, oriundas dos mais diversos setores sociais (além, naturalmente, do estilo oralizado, obtido, sobretudo, por uma supressão parcial dos sinais gráficos de pontuação e de introdução da fala das personagens; a simpatia do narrador pelas personagens que simbolizam valores ligados à democracia, ou mesmo a aberta contraposição para com os comportamentos autoritários, a exemplo dos cegos "malvados" no Ensaio sobre a cegueira; o recurso à ironia, a qual permite a manifestação do discurso do outro (inclusive das personagens simbólicas do autoritarismo, a exemplo das funerárias, asilos, hospitais e seguradoras em As intermitências da morte). No entanto, tais vozes são problematizadas, de modo algum por uma intromissão monológica do narrador, mas por meio da ironia. 
13. O conceito de totalidade admite a compreensão da realidade como um todo estruturado, que se desenvolve e se cria, repleto de contradiçoes em devir, conforme Kosik (Dialética do concreto). Assim, percebemos diversas totalidades ao longo da narrativa em análise.
Apesar de esses elementos serem suficientes para comprovar uma estética democrática em José Saramago, queremos enfatizar o princípio estrutural que cremos ser a base de sustentação do primado democrático na obra do escritor. O Ensaio sobre a lucidez, seguramente o mais político dos romances do Nobel de 1998, apresenta - conforme pretendemos demonstrar - o princípio estrutural dialético que, em nosso entendimento, também orienta a estrutura dos demais romances do escritor.

O Ensaio sobre a lucidez não apresenta uma subdivisão marcada tipograficamente com paratextos de capítulo, de unidades, de partes ou de índice numérico. No entanto, parece-nos possível atribuir a designação de capítulos aos momentos em que o parágrafo textual é recuado para, aproximadamente, pouco acima do meio da página. Tomamos, então, cada página que assim se materializa como o início de um capítulo que auxilia na exposição de nosso argumento. Essa divisão em prováveis capítulos não nos é original, uma vez que exposta por Seixo. Porém, propomos uma refração dessa proposta, ou seja, uma reordenação.

Do capítulo um ao cinco, a primeira totalidade, ${ }^{13}$ representa-se o dia de eleições municipais em país indeterminado. A essa situação de aparente normalidade democrática, a tese, contrapõe-se uma posição antitética, simbolizada no voto em branco de $83 \%$ dos eleitores da capital do país. O governo não compreende (ou não quer compreender) o voto em branco e toma uma série de medidas crescentemente autoritárias, a exemplo de pôr espiões nas ruas, interrogar pessoas, decretar o estado de exceção e depois o estado de sítio, além de prender cerca de quinhentos cidadãos para interrogatório por meio do polígrafo. O governo age como se o voto em branco fosse um ato criminoso contra a democracia. Os cidadãos, por sua vez, a cada ato autoritário dos governantes, reagem de modo pacífico, ordeiro e democrático. A partir desse choque de contradições, a elite política dirigente opera uma mudança qualitativa ao decretar o estado de sítio e retirar-se da capital, inaugurando uma segunda totalidade. Frisemos que na primeira situação total já temos a explicitação do conflito que perpassará toda a narrativa, ou seja, a tensão entre o governo e a sociedade.

Com a saída do governo e de instituições estatais da capital, como a polícia, inaugura-se a segunda totalidade, entre os capítulos seis e onze, na qual os diálogos entre os governantes e suas ações revelam o desejo de que impere na cidade um estado de natureza nos moldes de Hobbes. Factualmente, a cidade é isolada, compondo um cenário em alguns aspectos símile ao isolamento dos cegos no Ensaio sobre a cegueira, com o abandono dos cidadãos e ameaças para aqueles que tentassem sair do isolamento. Nessa totalidade, a posição do governo perante os "brancosos" assume a função da tese 
dialética, cujo teor podemos perceber na voz da personagem presidente, em discurso aos cidadãos sitiados:

Falo-vos com o coração nas mãos, falo-vos despedaçado pela dor de um afastamento incompreensível, como um pai abandonado pelos filhos a quem tanto amara [...]. é certo que vos encontrais cercados, rodeados, confinados dentro do perímetro da cidade, que não podeis sair dela, que se o tentais sofrereis as consequências de uma imediata resposta pelas armas, mas o que não podereis nunca é dizer que a culpa a têm estes a quem a vontade popular, livremente expressa em sucessivas, pacíficas e leais disputas democráticas, confiou os destinos da nação [...]. Vós, sim, sois os culpados [...]. Agora sois uma cidade sem lei. Não terei aqui um governo para vos impor o que deveis e o que não deveis fazer, como deveis e como não deveis comportar-vos, as ruas serão vossas, pertencem-vos, usai-as como vos apeteça, nenhuma autoridade aparecerá a cortar-vos o passo e dar-vos o bom conselho, mas também, atentai bem no que vos digo, nenhuma autoridade virá proteger-vos de ladrões, violadores e assassinos, essa será a vossa liberdade, desfrutai dela. Talvez imagineis [...] que sereis capazes de organizar melhor e melhor defender as vossas vidas que o que em favor delas nós havíamos feito com métodos antigos e as antigas leis. Terrível equívoco o vosso. Antes cedo que tarde sereis obrigados a tomar chefes que vos governem, se é que não serão eles a irromper bestialmente do caos inevitável em que ireis cair. ${ }^{14}$
O discurso do presidente não deixa dúvidas quanto ao estado de sítio, (expressões sublinhadas), à tática de culpar os cidadãos pelo uso do voto em branco (grifos em itálico) e sobretudo, quanto ao manifesto desejo de uma situação de violências e caos (expressões em negrito), em acordo com o hipotético estado de natureza hobbesiano, e a consequente justificação da necessidade do Estado e do governo. É interessante como o estado de natureza evocado pelo presidente condiz com a teoria contratual do poder absoluto do governante, característica que recrudescerá no decorrer da narrativa, sobremaneira pelas ações do primeiro-ministro e do ministro do interior.

A posição antitética estabelece-se com o comportamento dos cidadãos, os quais convivem pacificamente, solidariamente, guiados por princípios democráticos, ou seja, mais harmônicos com o hipotético estado de natureza de Rousseau. Em dado momento, o presidente da câmara municipal, ao percorrer a cidade buscando averiguar se o caos se instala, constata que tudo contradiz os desejos e prédicas do governo:

O presidente da câmara municipal [...] procura agora indícios de desleixo, de abandono, de deterioramento, e, pelo menos à primeira vista, não os encontra. As lojas e os grandes armazéns estão abertos, ainda que não pareça que estejam a fazer negócio por aí além, os automóveis circulam sem mais impedimentos que um ou outro engarrafamento de pouca monta, à porta dos 
15. SARAMAGO. Ensaio sobre a lucidez, p. 118.

16. GENETTE. Figuras. Palimpsestos. A literatura de segunda mão. bancos não há filas de clientes inquietos, aquelas que sempre se formam em alturas de crise, tudo parece normal, nem um só roubo de esticão, nem uma só briga de tiros e navalhas, nada que não seja esta tarde luminosa. ${ }^{15}$

Com efeito, a população se solidariza e convive sem maiores problemas, revelando valores democráticos, a exemplo das mulheres que saem às ruas para limpá-las diante da greve dos lixeiros, organizada maquiavelicamente pelo governo. Este, em um movimento crescente autoritário, revelador de sua perda de poder, tenta impor o caos violento na cidade sitiada, por exemplo, explodindo uma bomba no metrô. Os cidadãos, todavia, persistem em sua conduta coletivista, também de forma recrudescente.

Nos capítulos dez e onze, o foco narrativo se volta par as reuniões do governo, com relevantes diálogos dialéticos entre os ministeriais. Pelo diálogo, os ministros da justiça e da cultura compreendem o voto em branco como uma manifestação de lucidez e pedem demissão. De outro lado, o primeiro-ministro, especialmente, propõe que se trate o voto em branco como uma nova manifestação da cegueira branca que acometeu o país quatro anos antes, estabelecendo uma "transtextualidade" ${ }^{16}$ com o Ensaio sobre a cegueira, cujo entendimento passa a ser importante para se compreender o Ensaio sobre a lucidez. Uma missiva chega ao governo, enviada pela personagem primeiro cego do romance anterior, informando sobre o fato de a mulher do médico não ter perdido a visão assassinado um homem. $\mathrm{O}$ ministro do interior passa então a postular que a mulher é a culpada pelo fenômeno do voto em branco e infiltra três agentes na cidade sitiada para que colham provas de sua culpa e dolo. Com isso, opera-se uma mudança dialética da cidade sitiada, com as contradições entre os desejos de violência por parte do governo e as reações pacíficas dos cidadãos para a cidade ainda sitiada, mas agora com os agentes infiltrados, e uma acentuação das relações dialógico-dialéticas entre as personagens: o governo o comissário de polícia; o comissário de polícia e a mulher do médico; sem, contudo, excluir o conflito mais profundo entre governo e sociedade.

Essa nova totalidade, a terceira, entre os capítulos doze e dezenove, é permeada pela contradição entre o desejo do governo de culpar a mulher do médico a qualquer custo, mesmo sem provas, e a transformação dialética da personagem comissário de polícia, a qual, depois de perceber que a mulher é inocente e que os planos do governo são imorais e ilegais, recusa-se a colaborar com os governantes. O governo serve-se da mídia para divulgar uma fotografia em que a mulher do médico é apontada como a líder do voto em branco, esperando, com isso, que a população reaja negativamente para com a mesma. No entanto, o comissário de polícia, já consciente da inocência da mulher do médico, consegue divulgar uma carta em um jornal de oposição, na 
17. SARAMAGO. Ensaio sobre a lucidez, p. 308. qual esclarece os planos imorais e ilegais dos governantes. Essa carta, após ser publicada, é apreendida e o jornal censurado, mas a população se encarrega de reproduzir fotocópias dos exemplares não apreendidos pelo governo e espalha pela cidade sitiada. A dialética das propagandas se estabelece em um movimento dinâmico, como podemos perceber nas manchetes dos jornais. Da propaganda governamenta sobressaem manchetes como "Esta mulher matou", "Outro Crime da Mulher Suspeita" ou "Um Assassinato Há Quatro Anos”, revelando a cumplicidade entre a mídia e o governo. A antítese se faz pela manchete do jornal que publica a carta do comissário, intitulada "Que Mais Nos Falta Saber", sendo esse título "ambíguo, tanto podia significar isto ou aquilo, e igualmente os seus contrários” ${ }^{17}$ De fato, a ambiguidade fora intencionalmente instalada pelo editor do jornal para conseguir passar o texto pela censura, sendo o texto exatamente o contraditório daquilo que constituía a tese dos dirigentes políticos, ou seja, inocentava a mulher do médico e revelava os planos nefastos dos dirigentes políticos.

Em uma crescente tomada de posições antidemocráticas, o governo, enfim, efetua a superação dialética, o salto qualitativo, ao assassinar o comissário e a mulher do médico, revelando sua essência ditatorial sob a aparência democrática ao mesmo tempo em que os cidadãos configuram a antítese corporificada na posição democrática. $\mathrm{O}$ explicit narrativo e textual assim é expresso:
A mulher aproxima-se da grade de ferro, põe-lhe as mãos em cima e sente a frescura do metal. Não podemos perguntar-lhe se ouviu os dois tiros sucessivos, jaz morta no chão e o sangue desliza e goteja para a varanda de baixo. O cão veio a correr lá de dentro, fareja e lambe a cara da dona, depois estica o pescoço para o alto e solta um uivo arripiante que outro tiro imediatamente corta. Então um cego perguntou, Ouviste alguma coisa, Três tiros, respondeu o outro, Mas havia também um cão aos uivos, Já se calou, deve ter sido o terceiro tiro, Ainda bem, detesto ouvir os cães a uivar..$^{18}$

O desenlace, no sentido estabelecido pelo formalismo russo ou pelo estruturalismo, claramente não resolve o conflito profundo da narrativa, ou seja, a dialética entre governantes e governados, cujo estopim consubstancia-se pela maciça votação em branco. Desse modo, não nos parece plausível afirmar que o desfecho representa a vitória dos governantes, a descrença na ação coletiva e no homem, tampouco a sugestão de substituição do regime político democrático por outro qualquer, mesmo um regime comunista. Com esse modo de explicação, isola-se a parte final - sobreposta à totalidade -, sem mencionar que tal interpretação anula o movimento de contradições, sempre em devir.

Primeiramente, é necessário e não contingente perceber a estruturação do romance em totalidades dialéticas, nas quais a lei da unidade de contradições é visível. Não nos parece 
19. SARAMAGO. Ensaio sobre a lucidez, p. 101, grifo nosso. adequado pensar as diversas contradições em termos dicotômicos, posto que tal ação reduz o movimento à nulidade. É no inter-relacionamento entre as atitudes dos governantes e as dos governados que se opera o devir no universo ficcional, uma jamais anulando a outra, mas conservando traços essenciais elevados de nível a cada nova totalidade. O movimento, então, obedece à lei dos saltos, segundo a qual ocorre uma mobilidade quantitativa contínua que enseja o salto qualitativo, a mudança de nível, notadamente descontínua. Assim, ao longo do todo narrativo, há um devir contínuo representado nas crescentes ações autoritárias do governo e a antítese corporificada nas recrudescentes ações democráticas dos cidadãos, e um movimento descontínuo assinalado em momentos de crise, sendo a mais intensa a ação violenta e assassina do governo no explicit do romance, o que revela sua essência antidemocrática.

Todo esse movimento de contradições assemelha-se a uma espiral, em que a totalidade anterior é reenglobada e superada mantendo, todavia, resíduos da situação que a precede. Notese a passagem de uma totalidade para outra, em que o conflito entre os governantes e os cidadãos vai mudando de nível, mas sem recusar integralmente a contradição precedente.

Em um segundo momento, atentemos para a inadequação de explicações sentenciosas ao explicit, em seu tom supostamente pessimista. O narrador de Ensaio sobre a lucidez acompanha com simpatia e com um posicionamento axiológico positivo os cidadãos, além de tecer comentários irônicos em relação aos governantes. Ora, a ênfase axiológica na posição democrática dos "brancosos" pode ser indicativa de uma valoração da conduta cidadã, exemplarmente na ação coletiva como meio de emancipação política, ao mesmo tempo em que parece condenar o autoritarismo governamental. Desse modo, afirmar que o romance efetua uma crítica à democracia (há uma crítica à democracia deturpada), ou que propõe uma organização comunista, parece-nos uma demasia interpretativa, dificilmente sustentável com um exame rigoroso do princípio estético dialético. No próprio corpo textual esclarece-se o motivo do voto em branco, superando-se uma ideia de que o romance proponha uma radical e divergente organização política quanto à democracia:

Alguns sugeriam que fosse um grupo falar com o presidente da câmara municipal, oferecer leal colaboração, explicar que as intenções das pessoas que haviam votado em branco não eram deitar abaixo o sistema e tomar o poder, que aliás não saberiam que fazer depois com ele, que se haviam votado como votaram era porque estavam desiludidos e não encontravam outra maneira de que se percebesse de uma vez até onde a desilusão chegava. ${ }^{19}$

Explicitamente, afirma-se que não era intenção dos "brancosos" derrubar o sistema e tomar o poder, mas que estavam 
desiludidos. Desilusão com a democracia? Mais provável é atribuir a desilusão ao comportamento das elites políticas, as quais reduzem a democracia ao seu aspecto formal, enquan to regras procedimentais para tomada de decisões - e nem estas são respeitadas. A substância da democracia, ou seja, a efetivação dos princípios de igualdade e liberdade, sobretudo no que tange ao atendimento das demandas sociais, é evasiva e de insuficiente concreticidade. Logo, a desilusão passa pela falta de democracia substancial, aspecto que remete à ação dos governantes e não a uma crítica simples ao regime democrático. A passagem textual citada acima permite que afirmemos o teor de crítica social à imoralidade e ao autoritarismo da classe política, a qual esvazia a democracia e a reduz a um mero ritual eleitoral, e não ao regime democrático em seu estatuto ontológico.

Portanto, considerando-se o movimento dialético arquitetural e o próprio conteúdo da narrativa, uma explicação para o explicit de Ensaio sobre a lucidez exige, ao lado da carga simbólica e polissêmica do diálogo final entre os cegos (possivelmente se tratam de dois cegos, embora o segundo não seja indubitavelmente qualificado), o retorno da espiral dialética para o incipit e à epígrafe, formando uma nova totalidade.

Essa quarta totalidade, apreendida no cotejo entre a revelação da feição ditatorial e autoritária do governo e a persistência da ação humanista e democrática dos cidadãos, envolve

a situação total inicial, marcada pela "normalidade" democrática - o dia de eleições - e a antítese do voto em branco, para revelar que a situação inicial de "normalidade" democrática já trazia em si a contradição: a desilusão da sociedade para com a classe política e a falta de democracia substancial. O salto dialético opera-se com os $70 \%$, e depois $83 \%$, de votos em branco e as crescentes ações antidemocráticas do governo. Logo, a situação inicial não era de equilíbrio, mas de tensão entre contraditórios, os quais seriam postos a nu pela maciça votação em branco. Ou seja, pela lei da espiral, percebemos, sob a aparência de "normalidade" democrática, a essência de um todo dialético estruturado. Mantém-se a cidade, os governantes e os governados, porém, agora, com uma elevação de nível: o governo autoritário e os cidadãos democráticos.

A partir dessa percepção, podemos efetuar o retorno à epígrafe, assim materializada: "Uivemos, disse o cão. Livro das Vozes" ${ }^{20}$ Posicionada antes do texto romanesco, a referida epígrafe é enigmática, não apresenta um sentido à primeira vista. Somente depois da leitura do todo narrativo o movimento da arquitetônica textual solicita o retorno ao início, agora, porém, com um sentido, se não lapidar, ao menos sugerido. O explicit, citado anteriormente, revela o assassinato da mulher do médico e de seu cão - o mesmo que a acompanhara e lhe lambera as lágrimas no Ensaio sobre a cegueira - pelo agente enviado pelo governo. A despeito de toda a sua simbologia, ${ }^{21}$ amiúde associado a valores humanistas nos
20. SARAMAGO. Ensaio sobre a lucidez, $\mathrm{s} / \mathrm{p}$, grifo do autor.

21. A família de personagens caninos como símbolo de algum comportamento humanista e Pode-se citar, a título de exemplificação, os seguintes cães: Constante, em Levantado do chão Constante, em $A$ jangada de pedra o cão das lágrimas, nos Ensaios; Achado, em $A$ caverna. A relaçấo com santos é constantemente aventada pelo próprio narrador que, no entanto, não os nomeia. Segundo a tradição cristã, São Lázaro, São Roque, Santa Margarida de Cortona e São João Bosco figuram entre os santos cujas historias relacionam-se com cães, remetendo a relações de amizade e, não raro, episódios em que os animais ajudam os homens. 
romances de José Saramago, o cão emite um uivo arrepiante diante da morte da dona. Em seguida, o narrador nos relata o diálogo entre dois cegos, em que um deles declara que detesta ouvir os uivos dos cães. Ora, na epígrafe, ficcionaliza$\mathrm{da}$, o imperativo verbal se faz presente no discurso indireto do cão, traduzido no plural "uivemos". Simetricamente, há a proposição para que "uivemos" como o cão da narrativa "uivou" diante do assassinato de sua dona; assim, ao mesmo tempo, o "uivar" adquire uma significação segunda, distante da ordem normal de compreensão do significado da palavra ao associar-se ao diálogo dos cegos, relacionando, enfaticamente, a cegueira branca (cegueira moral) do Ensaio de 1995 ao universo ficcional do Ensaio de 2004. Por isso, "uivar" pode ser associado ao ato de ver e agir, como fizeram os cidadãos "brancosos", o comissário de polícia e a mulher do médico, em contradição com a opção de não "uivar" e de não avalizar o "uivo", postura atrelada aos cegos, ou seja, àqueles que não veem e não agem. Com isso, o simbolismo da contradição entre cegueira e lucidez adquire proposição para a ação lúcida, resultante do ato de ver a realidade em suas contradições. Desse modo, "uivar" sintoniza-se com a visão e a ação, ao passo que não "uivar" coaduna-se à cegueira e a inação, revelando o tom axiológico do romance.

Todavia, é imperioso reconhecer que essa nova totalidade não se pretende como uma resolução do conflito dialético da narrativa, mesmo porque se assim se propusesse tornaria o romance de um proselitismo dogmático, além de imobilizar o devir. Essa nova totalidade apresenta-se igualmente contraditória, transitando da imediaticidade de uma realidade ficcional aparentemente normal, equilibrada, sem conflito, para o desvelamento da mediaticidade essencial, uma realidade ficcional desde o começo caracterizada pela tensão de contrários. Em outras palavras, a nova totalidade revela a essência antidemocrática do governo, a carência de uma democracia substancial e o contraponto simbólico expresso no ser democrático dos cidadãos. O retorno espiral à epígrafe revela a indicação de um posicionamento avalizador de condutas pautadas pela democracia, evidenciando o teor axiológico da narrativa em acordo com a forma dialética da estrutura, em constante devir. Não há uma explicitação do que acontece depois do assassinato das personagens comissário de polícia e mulher do médico (e do cão), abrindo-se o desenlace para a sensibilidade do leitor e para consequências semânticas e ideológicas extratextuais.

A totalidade geral do universo romanesco evidencia a noção de movimento dialético que perpassa toda a narrativa. A TESE apresenta-se como a pseudoconcreticidade, nos moldes de Kosik, revelando uma aparente normalidade, um aparente equilíbrio. A SINTESE, por sua vez, não soluciona o conflito, de maneira a instalar um estado final sem ação significativa, mas envolve a TESE e a ANTÍTESE de maneira a revelar a realidade concreta da TESE em sua essência contraditória. 
Igualmente, imprime o devir para além do interior do universo ficcional, indeterminado, inconcluso. Observemos que a lei da espiral faz-se visível no movimento de uma totalidade para outra, por meio do choque de contradições em um devir contínuo e descontínuo, demonstrando as leis da unidade das contradições e dos saltos. Com essas figuras esquemáticas, sem a pretensão de esgotar as múltiplas possibilidades de análise do romance em questão, tencionamos tornar mais objetiva a abstrata estrutura de Ensaio sobre a lucidez, notadamente regida por um princípio dialético-democrático.

Com a explanação acerca do Ensaio sobre a lucidez, cremos ter demonstrado razoavelmente que a valoração axiológica em causa da democracia na obra saramaguiana - além de expressar um reflexo e uma refração do sentimento do autor em relação ao mundo extraliterário - encontra feliz realização em razão do princípio estrutural dialético, também este democrático. Assim, estendendo o argumento aqui apresentado às demais obras romanescas do escritor pensamos na plausibilidade de qualificar a estética de José Saramago como democrática, em franco dissenso para com a deturpada democracia da realidade concreta, confluindo o ficcional e o extraficcional para a formação de um poderoso questionamento ao leitor (e, consequentemente, sua desacomodação).

\section{REFERÊNCIAS}

AGUILERA, Fernando Gomes (Org.). As palavras de Saramago: catálogo de reflexões pessoais, literárias e políticas. São Paulo: Cia das Letras, 2010.

BOBBIO, Norberto. Estado, governo, sociedade: para uma teoria geral da política. Tradução de Marco Aurélio Nogueira. Rio de Janeiro: Paz e Terra, 1987.

BOBBIO, Norberto. O futuro da democracia. Tradução de Marco Aurélio Nogueira. Rio de Janeiro: Paz e Terra, 2000.

CHAUI, Marilena. Cultura e democracia: o discurso competente e outras falas. 13.ed. São Paulo: Cortez, 2011.

GENETTE, Gérard. Figuras. Palimpsestos. A literatura de segunda mão. Trad. Cibele Braga et alii. Belo Horizonte: Edições Viva Voz, 2010 .

HOBBES, Thomas. Leviatã, ou Matéria, forma e poder de um Estado eclesiástico e civil. Tradução: Rosina D'Angina. 2. ed. São Paulo: Martin Claret, 2012

KOSIK, Karel. Dialética do concreto. Tradução de Célia Neves e Alderico Toríbio. 4.ed. Rio de Janeiro: Paz e Terra, 1976.

LEFEBVRE, Henry. Lógica formal/Lógica dialética. Tradução de Carlos Coutinho. Rio de Janeiro: Civilização Brasileira, 1975.

\section{MARX, Karl. Posfácio à Segunda Edição Alemã (1872) do}

Primeiro Volume de $\mathbf{O}$ Capital. Disponível em <http://www.dorl. pcp.pt/images/classicos/oe3 me t2t08.pdf>. Acesso em 20 jan. 2014 
MEDVIÉDEV, Pavel. 0 método formal nos estudos literários introdução crítica a uma poética sociológica. Tradução de Sheila

Camargo e Ekaterina Américo. São Paulo: Contexto, 2012.

OZELAME, Josiele. 0 duplo, a lucidez e a morte: olhares

críticos. Tese (Doutorado em Letras) - Centro de Comunicação e Expressão, UFSC, Florianópolis, 2010.

ROUSSEAU, Jean-Jacques. Discurso sobre a origem e os

fundamentos da desigualdade entre os homens. Tradução de

Paulo Neves. Porto Alegre: L\&PM, 2014.

SARAMAGO, José. Ensaio sobre a cegueira. São Paulo: Cia das Letras, 1995

SARAMAGO, José. Ensaio sobre a lucidez. São Paulo: Cia das Letras, 2004.

SARAMAGO, José. Da estátua à pedra e discursos de

Estocolmo. Belém: UFPA, 2013a.

SARAMAGO, José. Democracia e universidade. Belém: UFPA 2013b.

SARAMAGO, José. Levantado do chão. São Paulo: Cia das Letras, 2013c.

SARAMAGO, José. Memorial do convento. São Paulo: Cia das Letras, 2013d.

SEIXO, Maria Alzira. Lugares da ficção em José Saramago.

Lisboa: Imprensa Nacional / Casa da Moeda, 1999. 